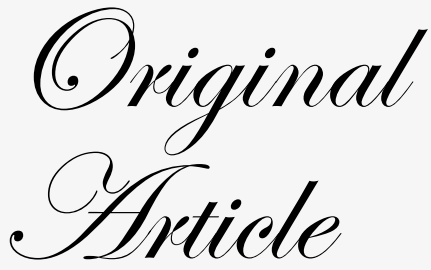

${ }^{1}$ Department of Gastroenterology, Indra Gandhi medical College, Shimla, HP, ${ }^{2}$ Department of Medicine Kangra H.P. India, ${ }^{3}$ Department of Medicine, ${ }^{4}$ Department of physiology

Corresponding author*: Dr. Sujeet Raina C-15, Type-5 residences, Dr. RPGMC Campus, Tanda, Kangra (HP), India-176001 email: sujeetrashmishera@ yahoo.co.in

\section{A study on the etiology of cirrhosis of liver in adults living in the Hills of Himachal Pradesh, India}

\author{
Brij Sharma ${ }^{1}$, Rishab Marwah ${ }^{3}$, Sujeet Raina ${ }^{2 *}$, Neetu Sharma ${ }^{4}$, \\ Madan Kaushik ${ }^{3}$, Satinder Singh Kaushal ${ }^{3}$
}

\section{ABSTRACT}

Aim: Cirrhosis of the liver is an important cause of morbidity and mortality in India. Currently no study exists on the disease from Himachal Pradesh, India. The purpose of this study was to evaluate epidemiological data on the etiological profile of cirrhosis of the liver in adults in a tertiary care hospital in a northern hilly state of Western Himalayas.

Materials \& Methods: A hospital based, cross sectional, observational study was conducted in the department of Medicine and Gastroenterology in a tertiary care centre of Himachal Pradesh, located in northern India from $1^{\text {st }}$ June, 2012 to $31^{\text {st }}$ May, 2013. In total, 178 patients who were diagnosed with cirrhosis on the basis of history, physical examination, biochemistry and radiology, and of age $>18$ years were included in the study. Detailed history, examination and investigations were carried out in each case as per protocol.

Results: Alcohol was the leading cause of cirrhosis in our study (62.9\%), hepatitis B was the second(10.1\%), Non-Alcoholic Steatohepatitis (NASH) was the third (7.9\%), and autoimmune the fourth (3.9\%) most common cause for cirrhosis. Hepatitis C was present in $2.8 \%$ of patients as a cause of cirrhosis. Wilson disease and cardiac cirrhosis were present in one patient each. In 9.6\% the etiology was cryptogenic.

Conclusion: The study identified alcohol as the leading cause of cirrhosis among people in the state. Measures for taking care of preventable risk factors are desired.

KEYWORDS: Cirrhosis, Etiology, India, alcohol

\section{Introduction}

The etiological spectrum of cirrhosis has varied among different geographical populations worldwide. Countries where alcohol consumption is high have reported it as the leading cause of cirrhosis, whereas countries where alcohol consumption is low or prohibited have showed viral hepatitis as the most common cause of cirrhosis. ${ }^{1}$ 
A systematic review of 118 studies including 23,797 patients showed alcohol (46\%) as the leading cause of cirrhosis followed by hepatitis C (35\%), hepatitis B (11\%) and other causes (12\%). ${ }^{2}$ In India as well the cause of cirrhosis has varied among different studies. In an earlier study, hepatitis B was found to be the leading cause of cirrhosis in the young (50.8\%) as well as in adults(44.3\%) followed by alcohol in the young(15.9\%) and in adults(35.8\%). ${ }^{3}$ Regional variation has also been observed from the study done on 175 patients with chronic liver disease in eastern India. It showed hepatitis B (35.4\%), hepatitis C (14.9\%), autoimmunity (2.8\%), Wilson's disease $(2.8 \%)$ and alcohol $(1.7 \%)$ as causes of cirrhosis. No etiology could be found in $15.8 \%$ patients. ${ }^{4}$ A study done in eastern Madhya Pradesh also reported their etiological spectrum for chronic liver disease with hepatitis B (40.6\%) as the most common cause for cirrhosis followed by alcohol (33.3\%), hepatitis C (3.3\%), and Non Alcoholic Fatty Liver disease or NAFLD (2.2\%) . No etiology could be found in $19.4 \%$ cases. ${ }^{5}$ In 2010 , there were an estimated 188,575 liver cirrhosis deaths in India, accounting for almost one-fifth (18.3\%) of the global liver cirrhosis death toll. ${ }^{6}$ Epidemiological data on the etiological aspects of cirrhosis of the liver are insufficient and have not yet been reported from Himachal Pradesh. Therefore, this study was planned and conducted in a tertiary care hospital providing gastroenterology services in Himachal Pradesh, India located in the Western Himalayas. This study is the first of its kind from this region.

\section{Materials and methods}

This cross sectional, observational study was conducted in a tertiary care centre in Himachal Pradesh, located in northern India from $1^{\text {st }}$ June, 2012 to $31^{\text {st }}$ May, 2013. All admitted patients who were diagnosed with cirrhosis on the basis of history, physical examination, biochemistry and radiology and of age $>18$ years were included in the study. Patients on immunosuppressants and unwilling to participate in the study were excluded. A detailed history was taken and a questionnaire was administered. The questionnaire enquired into various risk factors which included the following: history of alcohol consumption including amount and duration, CAGE score, history of blood transfusions, surgeries, needle prick injury, past history of jaundice and high-risk sexual behavior. A detailed clinical examination was performed and recorded in a proforma. For each patient, the following laboratory parameters were measured: haemogram, liver function tests, renal function tests and blood glucose. Viral markers like HBsAg and anti- HCV antibody by immunochromatographic rapid card test were done in each patient.

Ascitic fluid biochemistry and cytology were done in every patient with ascites. Serological markers like antinuclear antibodies (ANA), antibody against liverkidney-microsomes (LKM1), antismooth muscle antibodies (ASMA) and IgA tTG antibody were done in patients who were nonalcoholic and negative for viral markers. Serum ceruloplasmin, urinary copper levels and slit lamp examination for Kayser-Fleischer ring was done in young cirrhotics ( $<40$ years), who were nonalcoholic and negative for viral markers. All obese patients, in whom other etiologies of cirrhosis were ruled out, non-alcoholic steatohepatitis(NASH) was considered as the possible cause for cirrhosis. Ultrasound abdomen was done in all patients, followed by computed tomography if ultrasound was inconclusive or if there was evidence of hepatocellular carcinoma. Upper gastrointestinal endoscopy was performed in all patients unless contraindications like hemodyanamic instability, encephalopathy or respiratory failure were present. The study was approved by the institutional ethics committee.

\section{Results}

The study included a total of 178 patients; 124 (69.7\%) were males and $54(30.3 \%)$ were females. The male to female ratio was $2.3: 1$. The age group of the study population ranged from 18 years to 98 years. A total of $115(64.6 \%)$ patients were in the age group of 40-59 years. Mean age was 51.2 years. The causes of cirrhosis observed along with their frequencies are as shown in Table 1. The frequency distribution of etiology according to age and sex are shown in Table $\mathbf{1}$ and Table 2 respectively. Alcohol as the cause for cirrhosis was present across all age groups with a majority of patients falling in the age group 40-59 years(74.1\%). Alcohol was the leading cause of cirrhosis in males and it was 
Table 1: Etiology and age distribution

\begin{tabular}{|l|l|l|l|l|l|l|l|l|l|}
\hline Age & Alcohol & Hep B & Hep C & NASH & $\begin{array}{l}\text { Auto } \\
\text { Immune }\end{array}$ & Wilson & Cardiac & Cryptogenic & $\begin{array}{l}\text { Celiac } \\
\text { disease }\end{array}$ \\
\hline $18-29$ & 2 & 1 & 0 & 0 & 0 & 1 & 0 & 4 & 0 \\
\hline $30-39$ & 8 & 3 & 0 & 0 & 0 & 0 & 0 & 2 & 0 \\
\hline $40-49$ & 42 & 3 & 2 & 2 & 2 & 0 & 0 & 3 & 0 \\
\hline $50-59$ & 41 & 5 & 3 & 6 & 3 & 0 & 0 & 3 & 0 \\
\hline $60-69$ & 17 & 5 & 0 & 4 & 2 & 0 & 1 & 2 & 3 \\
\hline$\geq 70$ & 2 & 1 & 0 & 2 & 0 & 0 & 0 & 3 & 0 \\
\hline Total & $\begin{array}{l}112 \\
(62.9 \%)\end{array}$ & $\begin{array}{l}18 \\
(10.1 \%)\end{array}$ & $\begin{array}{l}5 \\
(2.8 \%)\end{array}$ & $\begin{array}{l}14 \\
(7.9 \%)\end{array}$ & $\begin{array}{l}7 \\
(3.9 \%)\end{array}$ & $\begin{array}{l}1 \\
(0.5 \%)\end{array}$ & $\begin{array}{l}1 \\
(0.5 \%)\end{array}$ & $\begin{array}{l}(7.6 \%) \\
(1.7 \%)\end{array}$ \\
\hline
\end{tabular}

Table 2: Etiology and sex distribution

\begin{tabular}{|l|l|l|l|l|l|l|l|l|l|}
\hline Sex & Alcohol & Hep B & Hep C & NASH & $\begin{array}{l}\text { Auto } \\
\text { Immune }\end{array}$ & Wilson & Cardiac & Cryptogenic & $\begin{array}{l}\text { Celiac } \\
\text { disease }\end{array}$ \\
\hline Male & $\begin{array}{l}106 \\
(94.6 \%)\end{array}$ & $\begin{array}{l}11 \\
(61.1 \%)\end{array}$ & $\begin{array}{l}2 \\
(40 \%)\end{array}$ & $\begin{array}{l}4 \\
(28.6 \%)\end{array}$ & 0 & 0 & 0 & $1(5.9 \%)$ & 0 \\
\hline Female & $6(5.4 \%)$ & $\begin{array}{l}7 \\
(38.9 \%)\end{array}$ & $\begin{array}{l}3 \\
(60 \%)\end{array}$ & $\begin{array}{l}10 \\
(71.4 \%)\end{array}$ & $7(100 \%)$ & $\begin{array}{l}1 \\
(100 \%)\end{array}$ & $1(100 \%)$ & $16(94.1 \%)$ & $3(100 \%)$ \\
\hline Total & $\begin{array}{l}112 \\
(62.9 \%)\end{array}$ & $\begin{array}{l}18 \\
(10.1 \%)\end{array}$ & $\begin{array}{l}5 \\
(2.8 \%)\end{array}$ & $\begin{array}{l}14 \\
(7.9 \%)\end{array}$ & $7(3.9 \%)$ & $\begin{array}{l}1 \\
(0.5 \%)\end{array}$ & $1(0.5 \%)$ & $17(9.6 \%)$ & $3(1.7 \%)$ \\
\hline
\end{tabular}

seen in 106 males out of 124 male patients (85.4\%) while NASH and autoimmune as causes of cirrhosis were more common among females. Out of 18 patients with hepatitis B, 8 patients were also alcoholic. In our study, alcohol consumption was higher among males, with $56.6 \%$ males consuming $>160 \mathrm{~g} /$ day while among females $50 \%$ consumed less than $80 \mathrm{~g} /$ day as shown in Figure 1. Majority of the patients (72.6\%) had been consuming alcohol for the previous $10-20$ years and 26.4\% patients had been consuming it for more than 20 years. 18 patients (10.1\%) were overweight and $10.1 \%$ patients were obese, in whom NASH was considered to be the possible cause for cirrhosis.

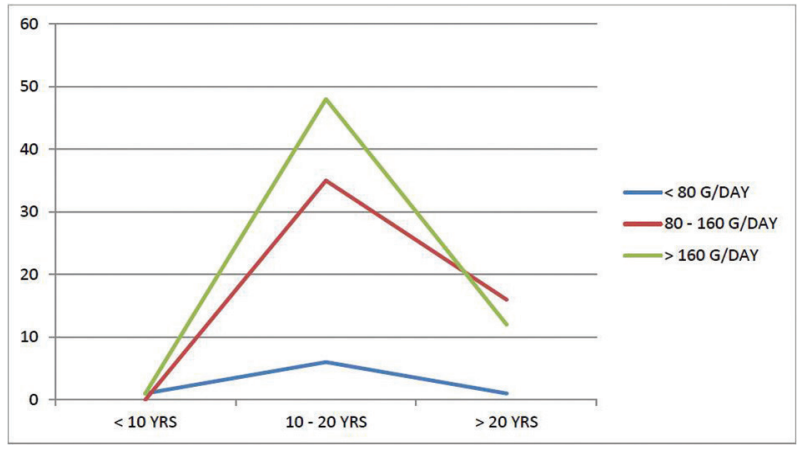

Figure 1: Pictogram showing a relation between quantity of alcohol consumed with duration

\section{Discussion}


Liver cirrhosis is largely preventable. Identifying and subsequently controlling the risk factors for cirrhosis have been recognized. The various etiologies of cirrhosis are alcohol, hepatitis B, hepatitis C, autoimmune, NASH, biliary cirrhosis, cardiac cirrhosis, inherited metabolic liver diseases including hemochromatosis, Wilson's disease, $\alpha 1$ antitrypsin deficiency and finally cryptogenic cirrhosis for which no underlying cause has been identified. ${ }^{1}$ In India, mortality due to liver cirrhosis increased from 77,741 (95\% uncertainty levels 52,196116,746 ) in 1980 to 188,575 ( $95 \%$ uncertainty levels $109,748-303,989)$ in $2010 .^{6}$

Alcohol was the leading cause of cirrhosis in our study (62.9\%), hepatitis B was the second (10.1\%), nonalcoholic steatohepatitis(NASH) was the third (7.9\%) and autoimmune the fourth (3.9\%) most common cause of cirrhosis. Hepatitis $\mathrm{C}$ was present in $2.8 \%$ of patients as a cause of cirrhosis. Wilson disease and cardiac cirrhosis were present in one patient each. In 9.6\% the etiology was cryptogenic. Among studies done in India it has been found that HBV (35-49\%) is the leading cause of cirrhosis..$^{3-5} \mathrm{~A}$ study done by Sarin et al showed HBV (44.3\%) followed by alcohol (35.8\%) as the leading causes of cirrhosis in adults. ${ }^{3}$ A study done in eastern Madhya Pradesh also reported their etiological spectrum for chronic liver disease with hepatitis B (40.6\%) as the most common cause for cirrhosis followed by alcohol (33.3\%), hepatitis C (3.3\%), NAFLD (2.2\%), and cryptogenic (19.4\%). ${ }^{5}$ Another study done in eastern India showed hepatitis B (35.4\%), hepatitis C (14.9\%), autoimmunity (2.8\%), Wilson's disease $(2.8 \%)$ and alcohol $(1.7 \%)$ as causes of cirrhosis. ${ }^{6}$

In India, the recorded alcohol per capita (15+ age in years) consumption (in liters of pure alcohol) was 4.3 in 2010 as reported by the WHO. In 2012, the age standardized death rates(ASDR), as per WHO, due to liver cirrhosis in India among males and females were 39.5 and 19.6 respectively, out of which alcohol attributable fractions(AAF) constituted $62.9 \%$ and $33.2 \%$ respectively. ${ }^{7}$ According to the alcohol atlas of India, the prevalence of alcohol use among men in Himachal Pradesh is between $25-49 \%{ }^{8}$ Consumption of liquor is perceived to be a part of the social and religious lives of the tribal population of Himachal Pradesh. ${ }^{9}$ It is evident from this study that regular, moderate alcohol consumption in middle age males is the dominant cause of cirrhosis in this part of world.

From analyzing the second most common cause of cirrhosis in our study, it can be established that India is considered to have an intermediate level of hepatitis B virus (HBV) endemicity with $3.7 \%$ point prevalence, that is, over 40 million HBV carriers. ${ }^{10}$ The prevalence of HBV estimated in Himachal Pradesh is 0.536 (CI 0.135- 0.937). ${ }^{11} \mathrm{NASH}$ was the third most common cause of cirrhosis in our study. Metabolic syndrome has emerged as a significant health concern as was observed in the newly diagnosed hypertensive patients in the state, reflecting the epidemiological transition experienced in this hilly region. ${ }^{12}$ Autoimmunity as the cause of cirrhosis was found exclusively among females in our study as all 7 patients of autoimmune etiology were female. Autoimmune hepatitis occurs more commonly in females. ${ }^{13}$ Hepatitis $\mathrm{C}$ is not a common cause of cirrhosis in this region possibly because of low prevalence in the area As the population prevalence of HCV infection in India is $1 \%{ }^{10}$ and a study has shown a relative absence of HCV infection in Shimla. ${ }^{14}$

South Asia, particularly India, requires priority attention to improve prevention and control of liver cirrhosis risk factors, considering that almost one fifth (18.3\%) of global liver cirrhosis deaths in 2010 occurred in India alone. ${ }^{6}$ Mortality as a result of cirrhosis has been steadily increasing in India since 1980, as has alcohol consumption. There has also been an increase in the prevalence of hepatitis $\mathrm{B}$ and $\mathrm{C}$ and diabetes (a major risk factor for nonalcoholic fatty liver disease (NAFLD). The favourable points of this study are that the causes of cirrhosis in this region were identified, which help us in predicting complications and to direct treatment decisions. Knowledge of the common causes also allows discussing their preventive measures. Focus on primary prevention by abstaining from alcohol consumption, preventive hepatitis B vaccination and adopting a healthy life style are the measures recommended.

\section{References:}

1. Schuppan D, Afdhal NH. Liver Cirrhosis. Lancet. 2008 Mar 8;371(9615):838-51. 
2. D’Amico G, Garcia Tsao G, Pagliaro L. Natural history and prognostic indicators of survival in cirrhosis: A systemic review of 118 studies. J Hepatol 2006; 44:217-31

3. SK Sarin, SChari, KRSundaram, RK Ahuja, BS Anand, SL Broor. Young v adult cirrhotics: a prospective, comparative analysis of the clinical profile, natural course and survival. Gut 1988; 29:101-07

4. Ray G, Ghoshal UC, Banerjee PK, Pal BB, Dhar K, $\mathrm{Pal}$ AK et al. Aetiological spectrum of chronic liver disease in eastern India. Trop Gastroenterol. 2000; 21:60-62

5. Trimukhe R, Rai R, Narayankar SM, Shewale S, Jagtap N, Rai S et al. Epidemiological spectrum of chronic liver disease in eastern Madhya Pradesh India. J Assoc Physicians India 2011;59:48

6. Mokdad AA, Lopez AD, Shahraz S, Lozano R, Mokdad AH, Stanaway J et al. Liver cirrhosis mortality in 187 countries between 1980 and 2010: a systematic analysis. BMC Medicine 2014;12:145.

7. WHO Global status on alcohol and health 2014 . Available from: www.who.int/substance_abuse/ publications/global_alcohol_report/en/[Last accessed on 07-12-2014]

8. Alcohol atlas of India. Available from: www.
indianalcoholpolicy.org/alcohol_atlas.html[Last accessed on 07-12-2014]

9. Romila B, Rakesh G, Mai C, Chauhan JK. Alcoholism - a social evil among the tribals of Kinnaur district of Himachal Pradesh. Journal of Farm Sciences 2011;1: 137-44.

10. NCDCNewsletter2014;JanMar,vol3.Availablefrom:http:// ncdc.gov.in/writereaddata/linkimages/NewsLtr0103 20146680274026.pdf[Last accessed on 07-12-2014]

11. Batham A, Gupta MA, Rastogi P,Garg Sreenivas V, Puliyel JM. Calculating prevalence of Hepatitis $\mathrm{B}$ in India: Using population weights to look for publication bias in conventional meta-analysis. Indian J Pediatr 2009;76:1247-57

12. Thakur S, Raina S, Thakur S, Negi PC, Verma BS. Prevalence of metabolic syndrome among newly diagnosed hypertensive patients in the hills of Himachal Pradesh, India. Indian J Endocr Metab 2013;17:723-26

13. Krawitt, E.L. Autoimmune hepatitis. N Engl J Med 1996; 334: 897-903

14. Ganju SA, Goel A. Hepatitis C virus activity in Shimla-A preliminary report. Indian J Med Microbiol 2001; 19:227 . 